\title{
Good on paper?
}

\author{
Are the days of print journals numbered - and if they are, what will that mean for how we interact \\ with the scientific literature?
}

The rise of the internet has brought with it much innovation with regard to publishing. Traditional print media such as newspapers, books, magazines and scholarly journals are no longer confined to paper and can be enhanced in a number of different ways in an online setting. The scientific community — both researchers and publishers - has wholeheartedly embraced web-based publishing, but print journals are still produced for the majority of titles.

The question of whether journals have a future in print has been around ever since their online presence began, but it has been brought into sharp focus by an announcement ${ }^{1}$ from the American Chemical Society (ACS) on 17 July, indicating that they will change the format in which most of their journals are printed. With the exception of the Journal of the American Chemical Society and their two review journals, ACS titles publishing primary research will be printed in a landscape fashion that puts two article pages side-by-side on a single physical page. These changes are accompanied by new pricing schemes that will eliminate discounts for hardcopy journals, while offering subscribers incentives to upgrade from print to digital formats.

\section{It will probably come to pass}

\section{that as this century grows}

\section{older, printed journals will be consigned to history.}

The ACS press release makes it clear that they will continue to produce printed journals throughout 2010, but what happens beyond that, "will depend on market conditions and customer demand during the next 12-18 months." It is difficult to imagine, however, that the changes being implemented in how the ACS is printing and pricing their journals is not a precursor to eliminating the hardcopy versions of some or all of their titles. And if indeed that is the case, would it be a bad thing? Members of the chemistry community are weighing in on both sides of the argument ${ }^{2-4}$.

The majority of chemistry papers appear online before being compiled into a physical issue and can be read long before the hardcopies are even dispatched from

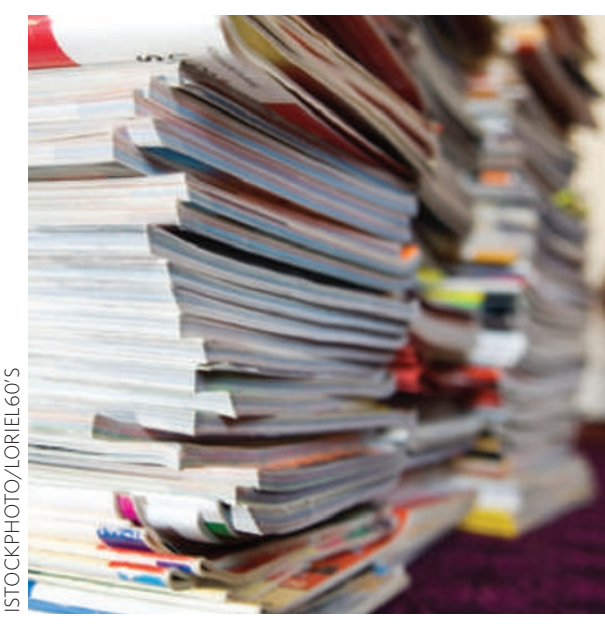

the warehouse. With e-alerts and RSS feeds (and these days Twitter too!), readers can be made aware of what a journal has published at a moment's notice. Online publication also enables articles to be enriched ${ }^{5}$ with features that offer the reader much more of an interactive experience than a printed article ever could. The manner in which the scientific literature is searched has also been revolutionized by the shift from print to online publication. Today, either through the use of specialized software or a commonor-garden web search engine, it is possible to track down articles written by a particular author, or those that feature a specific reaction or chemical substance in a matter of minutes.

These are undoubtedly incredibly useful developments, but it does mean that literature searching is now more focused, and although it is much easier to find things you are looking for, it is much harder to find potentially valuable information that you don't necessarily know to look for. Web-based articles with all their 'bells and whistles' serve many purposes, but browsing through them is just not the same as sitting down with a printed issue. The idea of a laboratory office filled with thumbed-through journals just asking to be read over a cup of coffee is perhaps nothing more than misplaced sentimentality, but what better way to stumble across a potentially useful reaction or interesting paper that you otherwise wouldn't have given the time of day to?

There are other considerations of a practical nature, however, that must be accounted for. There are many more chemistry journals now than there were 10 years ago, this one included. Many more pages are being printed and this - along with their subsequent distribution - has both a financial and an environmental cost. University libraries are not only straining under the physical weight of their collections, but also under economic constraints. The question becomes whether the business of printing journals is a sustainable one, rather than a debate over the relative merits of printed versus online formats.

It is often remarked that the demise of print journals is simply inevitable, and with the considerations outlined above, it is perhaps hard to argue the point. And in all likelihood, it will probably come to pass that as this century grows older, printed journals will be consigned to history. And in some ways, that would be a shame. Printed materials have their own charm and practicality - no batteries required! - and will always have a loyal following. Whereas some individuals may be happy to replace their dusty bookshelves and their contents with a plastic electronic reader of some description, many would shudder at the thought.

Moreover, should chemistry publishing become an online-only endeavour, the concept of 'issues' also comes into question. With the ability to dynamically group articles on a website using criteria such as dates or keywords, does journal content need to be collated into bite-sized chunks if print is no longer a consideration? And without issues, what becomes of cover images? These serve to advertise both the journal and people's work - many conference talks are proudly emblazoned with journal covers, as doubtless are many people's offices.

Assuming sustainable models, the continued co-existence of print and digital editions of journals (especially for those that publish more than just review and research articles) would satisfy the needs of all readers - but whether this is a realistic goal in the long term remains to be seen.

\footnotetext{
References

1. Available via http://bit.ly/4A35vm

2. http://www.nature.com/news/2009/090617/full/news.2009.576.html

3. Diederich, F. Nature 460, 33 (2009).

4. http://pipeline.corante.com/archives/2009/07/06/farewell_to_ hard_copies.php

5. Nature Chem. 1, 168 (2009).
} 